Arab World English Journal (AWEJ) Volume 12. Number1 March 2021

DOI: https://dx.doi.org/10.24093/awej/vol12no1.5

\title{
Interventions to Improve a Practicum Course for EFL Teachers in Saudi Arabia
}

\author{
Khadija A. Alamoudi \\ English Language Institute, King Abdulaziz University \\ Jeddah, Kingdom of Saudi Arabia \\ Email: khaalamoudi@kau.edu.sa
}

Received: 11/9/2020

Accepted: 1/22/2021

Published: 3/24/2021

\begin{abstract}
Although the Teaching Practicum (TP) course makes a significant contribution in preparing teachers, it remains lacking in many essential aspects. To fill in the gaps regarding literature, this research paper was designed to explore the views of three Master of Art (MA) TESOL studentteachers on the advantages they gained and challenges they faced during their TP course at a Saudi university. Participants were interviewed, observed, and the two reflective assignments of the course were analyzed to find answers to the research questions. The research questions focused on the instructional benefits of the TP course and the interventions needed to enhance the effectiveness of the course. The findings revealed that the practical teaching component was the most helpful part of the course and the peer-observation report was the most appropriate evaluation method. Moreover, the study found that the limitedness of the teaching timeframe poses a significant challenge, and hence increasing the teaching practice time was the most significant change the participants suggested. Finally, the study recommends interventions that will help improve the quality of the TP course.
\end{abstract}

Keywords: English language teaching in Saudi Arabia, Saudi EFL teachers, student-teachers, teaching practicum (TP), qualitative research

Cite as: Alamoudi, K. A. (2021). Interventions to Improve a Practicum Course for EFL Teachers in Saudi Arabia Arab World English Journal, 12 (1) 59-70.

DOI: https://dx.doi.org/10.24093/awej/vol12no1.5 


\section{Introduction}

As a significant part of English language teachers education, teaching practicum (TP) received considerable attention from educators and researchers (Köksal \& Genç, 2019). It is well established that teacher education programs provide student-teachers with a quality education that positively contributes to their future careers. Besides imparting the student-teachers' theoretical knowledge about teaching, these programs help them to develop their skills on a pedagogical and practical level. This development occurs because those students are likely to be exposed to various teaching aspects.

According to Haigh, Ell, and Mackisack (2013), the success of a TP course is an indicator for the success of teacher education programs. Besides linking related theories to the required practical knowledge about teaching, TP courses provide student-teachers with an opportunity to become familiar with the profession of teaching (Furlong, Hirst, \& Pocklington, 1988). TP should focus on helping student-teachers gain first-hand experience in different teaching aspects. Student-teachers might have some challenges in knowing the nature of their duties as teachers, comprehending the learner aspirations, and acquiring the critical analysis skills that will allow them to deal with different problems related to teaching. Thus, one may anticipate that TP should provide students with various opportunities to develop competencies in teaching and the required social/academic skills.

After reviewing the relevant literature, the author found that researchers have not given sufficient attention to TP in Saudi universities. Thus, to fill in this gap, the author conducted this study to explore the strengths and weaknesses of the pedagogical knowledge and practical aspects of the MA TESOL TP course at a Saudi university. It aims to find answers to the following questions:

1- How was the course helpful for student-teachers to develop their teaching skills? And which part was more helpful?

2- What were the instructional benefits they gained?

3- Do student-teachers think the evaluation methods used in the course were appropriate?

4- What were the challenges they faced during the course?

5- What are the interventions needed to enhance the effectiveness of the course?

\section{Literature Review}

Many studies have focused on TP as a significant part of teacher education programs. For instance, Ulla (2016) explored the practicum experience of 21 English language student-teachers from a private university in the Philippines. Ulla study revealed that student-teachers faced difficulties with teaching confidence, lack of teaching resources, and classroom management. Gujjar, Ramzan, and Bajwa (2011) conducted a study to examine a course that 650 studentteachers receive as part of their education. They randomly selected 25 student-teachers from 26 teacher training institutions in Pakistan to answer a 22-item questionnaire. Their study reported that the challenges are lack of demonstration lessons, the duration was insufficient to develop their teaching skills, and the evaluation methods were inappropriate. Yuan and Lee (2014) carried out a study to explore the cognitive change process of second language teachers and to improve the practicum course. They investigated the process of belief change during a TP course among three student-teachers in one of China's universities. Their study recommended that 
student-teachers need a supportive and open environment to maximize their learning during the course. They believe this would help promote the cognitive development of student-teachers and facilitate the change process of their belief.

In a more recent study, Köksal and Genç (2019) investigated what eight student-teachers in a Turkish university thought they learned during a TP course and the challenges they faced. Using qualitative methodology, they collected data using two methods: semi-structured questionnaires and reflective journals. The findings revealed that student-teachers typically learn "pedagogical strategies, developing professional identity, and developing positive feelings" (Köksal \& Genç, 2019, p. 895). The main challenges were "classroom management, time management, mixed-ability classes and difficulties in using technology" (p. 895). An interesting finding they reported was that the process helped student-teachers to raise their awareness about their actual strengths and weaknesses. Finally, participants shew progress in their instructional practice and teaching skills through in-class discussions and classroom observation sessions. Merç (2015) examined the satisfaction of 117 student-teachers in a Turkish university with the evaluation methods. The study found that the most effective measures were planningpreparation, general organization, and assessment by university supervisors. Furthermore, Çapan (2014) examined the changes in student-teachers beliefs about grammar instruction through the TP course. The examination revealed that the TP did not affect their beliefs about grammar instruction.

In the context of ELT in Saudi Arabia, Alamri (2018) used mixed method action research to examine 35 Saudi female student-teachers on the challenges they face when teaching during the TP course at Taibah University. The findings indicated that the observation period was moderately to extremely beneficial to the participants. As for challenges, the study found classroom-teaching skills to be moderately to low challenging to them. Alnajami (2018), in another research, attempted to assess the TP effectiveness in the University of Jeddah. By interviewing four school mentors, two university mentors, and 16 student-teachers teaching the English language, Alnajami collected data. The results showed that English language teaching pedagogical and contextual knowledge improved during the TP course. According to the study, the participants placed "importance on pedagogical knowledge and contextual knowledge as well as subject matter knowledge" (Alnajami, 2018, p. 47). The study also found that through teaching practice, the methodologies of English language teaching taught in a university course before the TP was reinforced during the TP. In the context of this university in Saudi Arabia and to the best of the author knowledge, no research has been done on TP. Thus, this study is one of the first studies that will help filling in this gap in the literature.

\section{Methodology}

Given its exploratory nature, the interpretive paradigm informed the philosophical assumptions underpinning this research. Creswell and Poth (2017) state that the most significant characteristic of the interpretive approach is that individuals attach different meanings to actions. Those meanings are primarily grounded in their knowledge. Thus, what an interpretive researcher mainly looks for are the different ways individuals understand a phenomenon and the subjective meaning they attach to it. As Neuman (2007) confirms, the most noticeable interest of interpretivism is the "systematic analysis of socially meaningful action" (p. 62). Therefore, interpretive researchers perceive reality as socially constructed (Mackenzie \& Knipe, 2006). On 
an epistemological level, constructivism assumes that the objective truth is not merely waiting out there for researchers to uncover it. Instead, when individuals engage with the realities in their world, truth exists (Crotty, 1998). It is the interpretive researcher task to explore the different realities individuals hold. Interpretive researchers also try to find the various meanings individuals attach to these realities and interpret them.

\section{Methods (Instruments)}

Considering all that is thus far discussed, tools used to collect qualitative data seem to be fitting well to answer the research questions. These tools allow researchers to collect the abundant information needed and the profundity of thought required to satisfy the exploratory demands that help understand the explored phenomena. To gather data for this research, the researcher utilized five qualitative data collection methods: semi-structured interviews, reflective portfolios, peer observation reports, classroom observations, and students evaluation form of the course. One-to-one semi-structured interviews were arranged, carried out, and recorded with all three participants. Classroom observation for student-teachers while practicing teaching done by the researcher was also one of the data collection methods. Likewise, student-teachers peer observation reports, their reflective portfolio, and evaluation form were among the sources. As for data management and analysis, the researcher transcribed the interview records. Then, she entered the data from all the five sources into MAXQDA 2020. The researcher thematically analyzed the data by extracting themes and subthemes inside the software. She then grouped similar subthemes and initiated the main themes. The researcher calculated frequencies of subtheme and used diagrams to help readers visualize the results.

\section{Participants and Setting}

The participants of this research were three students doing a TESOL Master in a Saudi university. They were female Saudis and aged 24 to 32 with a different range of teaching experience. While one of the participants had five-year language teaching to young learner experience, another had taught English to adults for two years, and the third had no chance to teach at all. To avoid revealing their identity, the researcher referred to them using pseudonyms. This sample represents the whole population of one section that took the TP course. Students who joined the MA TESOL program are either previous English language teachers or planning to become so upon completing the course. They were in the first semester of the second year of the program. The TP course theoretically examines current debates revolved around language teaching methodology. It also develops an understanding of language teaching as a profession employing readings, classroom discussions, and course assignments with an emphasis on reflecting on language teaching. It offers student-teachers an opportunity to teach a short session, generally 20 minutes, to foundation year program students. The course had three assignments: six hours of observed teaching practice where students observe other experienced teachers, peer observation report where students reflect on their colleagues teaching, and reflective practicebased teaching portfolio where students reflect on a minimum of 30 hours of their teaching.

\section{Finding} data.

This section presents the main findings of the research resulted from the analysis of the Ways in Which the Course Was Helpful 
Regarding the first research question: how the course was helpful to develop the studentteachers teaching skills, eight themes emerged. The following chart presents the themes and their frequency:

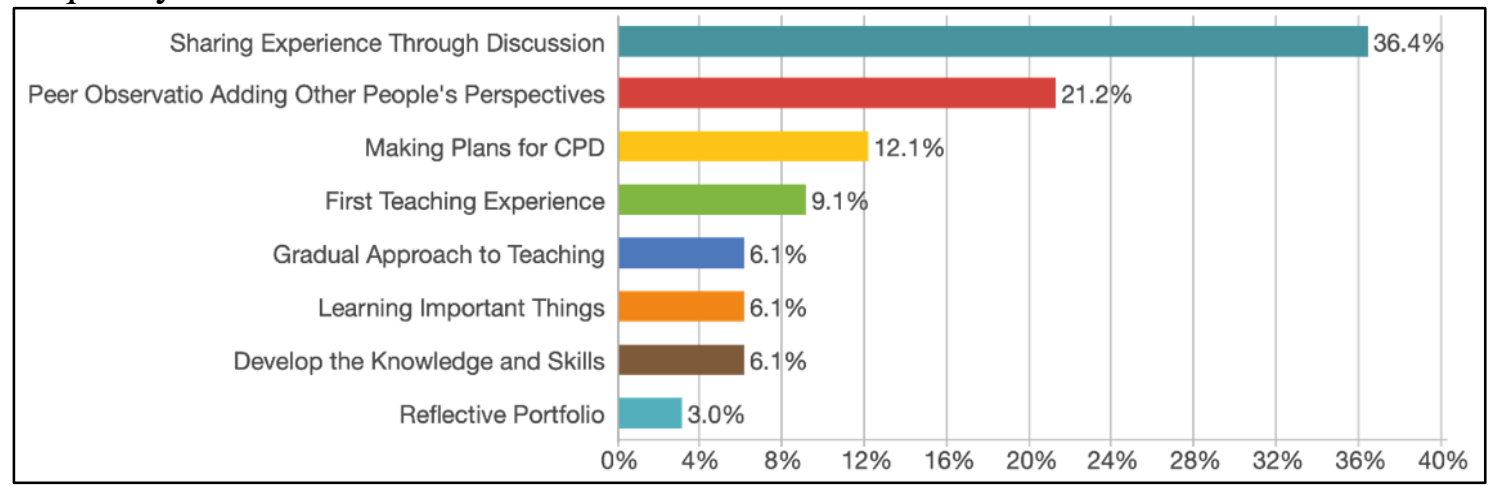

Figure 1. Ways in Which the Course Was Helpful

Sharing experience through classroom discussion is the most frequent theme amongst all the eight emerged themes (36.4\%), followed by adding other people perspectives through peer observation (21.2\%), making plans for professional development (12.1\%), and having first teaching experience $(9.1 \%)$. Getting a gradual approach to teaching, learning essential aspects, and developing knowledge and skills show the same frequency level (6.1\%). Finally, reflecting on their own experience is the least frequent theme (3\%). One of the participants, Haifa, reported the importance of classroom discussions in the interview:

like just the small discussions we had during lectures that are related to how we taught or what was different, sharing our experiences and thoughts and techniques ... something getting me to know more. This part really helped each one of us to say I used to do this to enhance the students' practice.

May, in her portfolio, expressed a similar opinion:

Through our many discussions in the teaching practice class, my instructor talked about her way of teaching grammar inductively, which we found useful.

The participants emphasized that peer observation helped them and enhanced their practice. For instance, Yara, in the interview, said:

I really liked the peer observation assignment as it gave me insights on certain things that I was doing while teaching and I wasn't really aware of; so, having someone to critically look at my teaching was really helpful.

In the same vein, May mentioned in the peer observation report how peer observation is significant for her:

This short experience with the observer's comments improved my awareness of different points.

\section{Parts of the Course That Was Helpful}

The chart in figure two shows how practical teaching is the most helpful part of the course $(46.2 \%)$, followed by observation $(34.6 \%)$, and finally assignments as the least helpful part $(19.2 \%)$. 


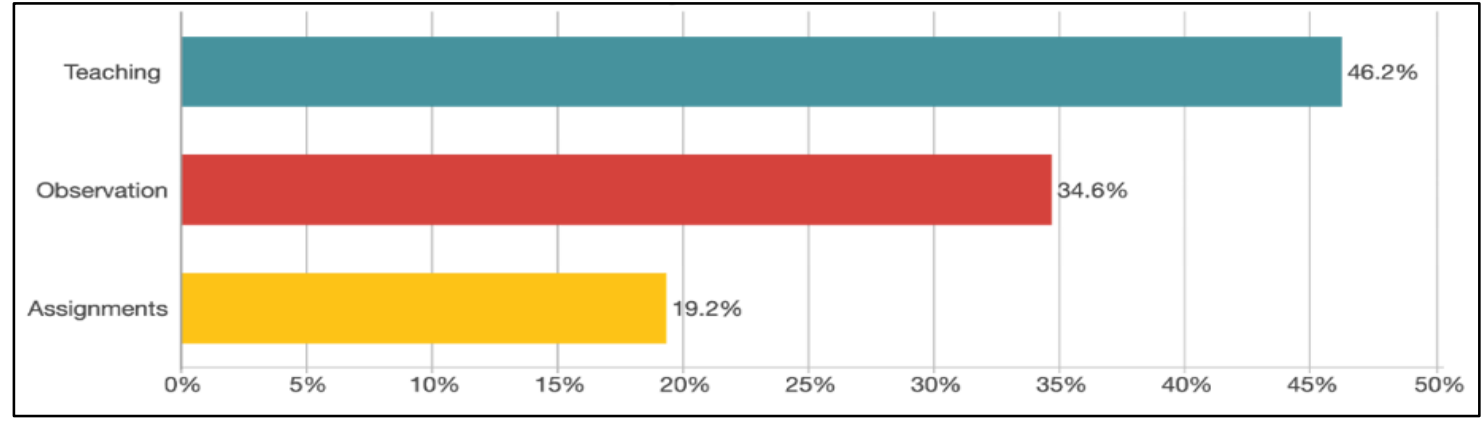

Figure 2. Parts of the Course That Was Helpful

When the researcher asked Yara in the interview about the most helpful part of the course, she enthusiastically confirmed:

the practical aspect of it! Of course! Especially teaching the 20 minutes, because I've got the opportunity to put what I've learned into practice.

In the peer-observation report, May explained some of the reasons for her perception that classroom observation is the most helpful part in enhancing teaching:

Observation was incredibly beneficial for me; the observer's feedback enlightened me regarding many of my mistakes. I was surprised by her comment on the use of colors on the board. I did not give much attention while I was teaching to use different colors.

\section{The Instructional Benefits}

As figure three shows, ten themes that show the instructional benefits the studentteachers gained from the course emerged.

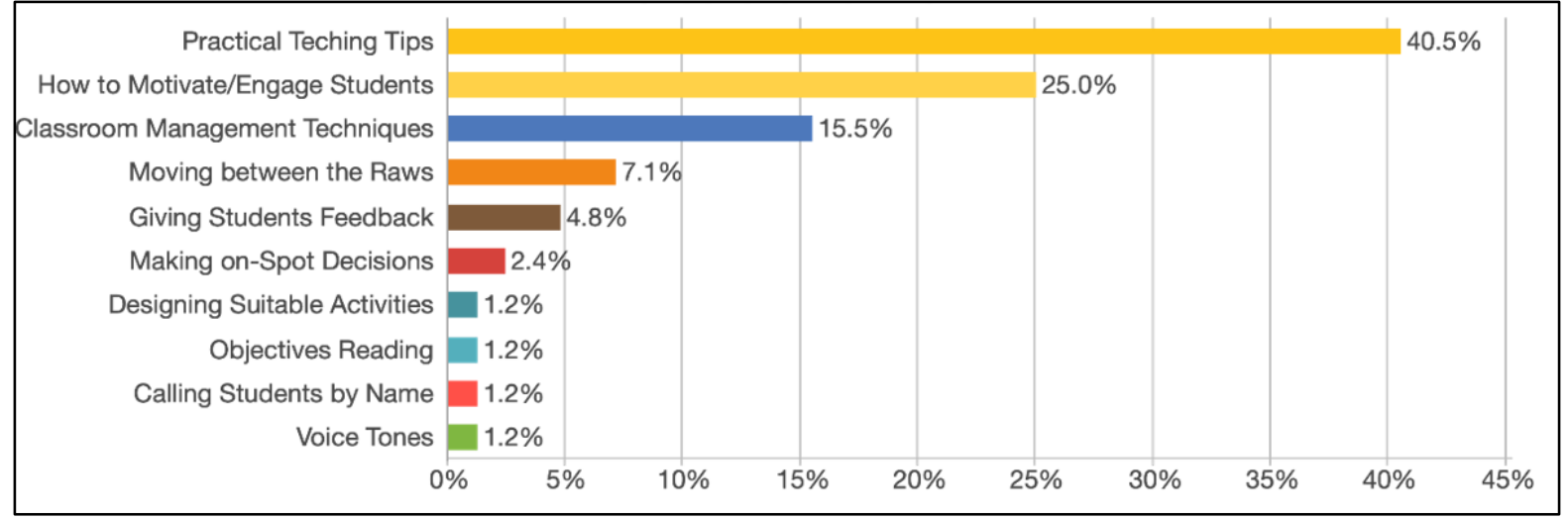

Figure 3. The Instructional Benefits

One of the practical teaching tips was using technology inside the classroom. As part of the classroom observation practice and when Yara gave the twenty-minute practical teaching session, her peers observed that she used technology efficiently to deliver the lesson. Using technology was also discussed during the feedback session and highlighted in the collected documents as a significant teaching aid. As for the second theme, engaging learners, May reported in her reflective portfolio that: 
One way of motivating students to learn is to link their learning with their personal lives. Thus, I asked my students what their life goals were. I also encouraged them to set academic goals ...

Concerning the third theme and as feedback to a colleague, Haifa wrote the following on her peer-observation report:

My colleague showed good class management and monitoring during activities. She was observing and moving around the class during the time of the activities.

\section{Appropriateness of the Evaluation Methods}

Analysis of the data shows that participants perceived peer-observation report as the most appropriate evaluation method. The chart in figure four displays that the peer-observation report received a 62.5 percent preference rate, followed by the reflective portfolio with 25 percent. Some participants suggested adding classroom discussion as a method of evaluation, which received 12.5 per cent.

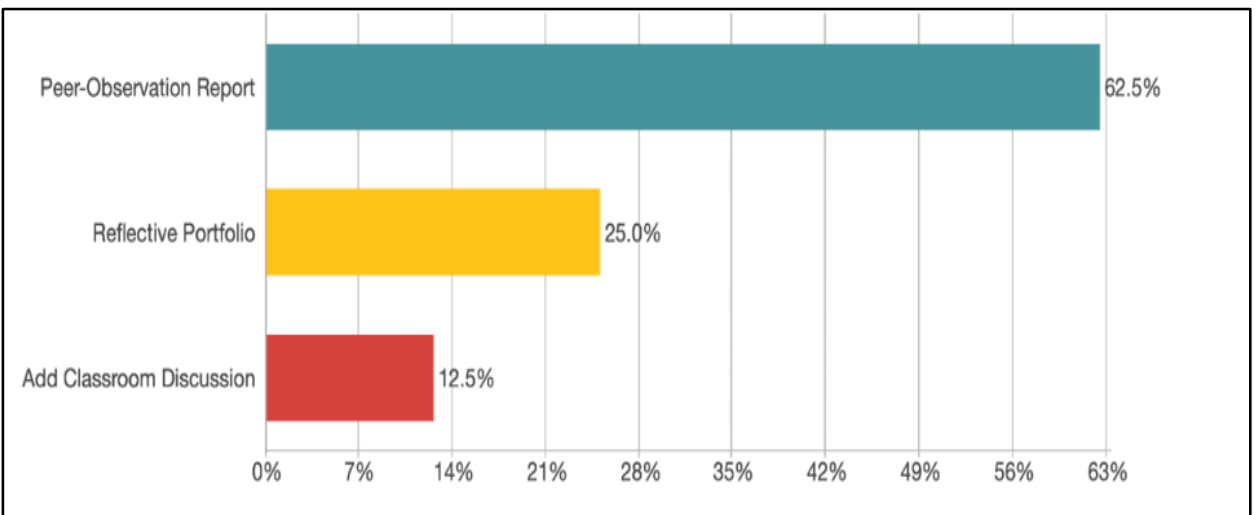

Figure 4. Appropriateness of Evaluation Methods

In her peer-observation report, Haifa indicated:

peer observation assignment provided me with an opportunity to look at areas of good practice and areas for improvement from another perspective.

Yara, in the interview, emphasized that the reflective portfolio was beneficial:

I really liked reflection assignments, especially the third assignment, because it was a new thing for me to reflect on my teaching practice. I just think about it but never really wrote about it this way.

Remarkably, May suggested a new evaluation method during the interview:

add like five or ten grades for classroom discussions to encourage students to discuss.

\section{Challenges Student-Teachers Faced during the Course}

Nine themes emerged from the data were related to the challenges the participants faced during the course. The most dominant theme was the limited teaching time, with 61.9 percent of the total data. The following chart illustrates all of them: 


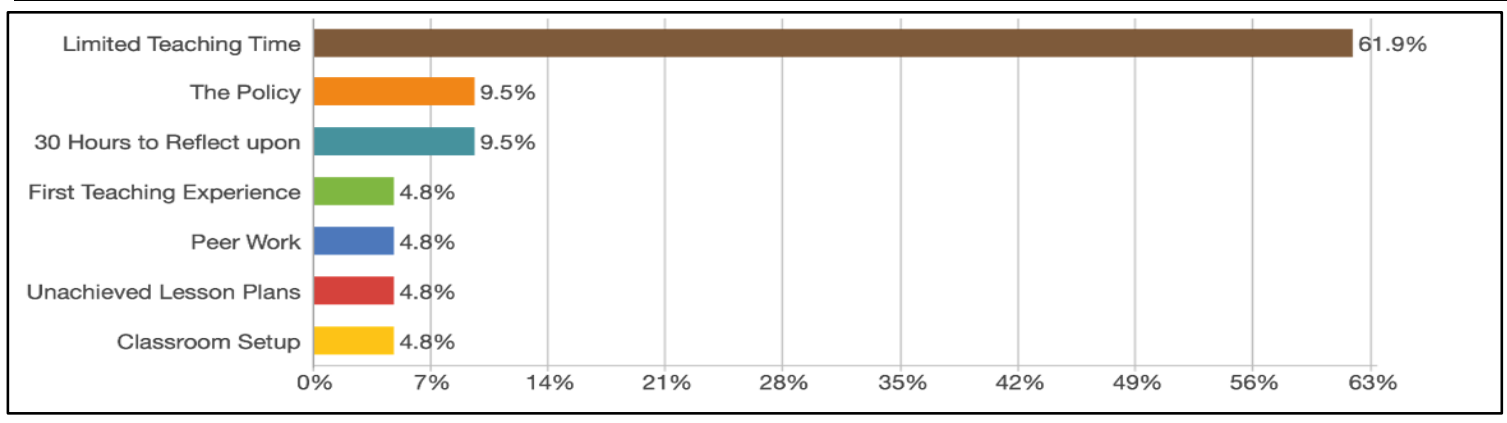

Figure 5. Challenges Student-Teachers Faced during the Course

The participants, in three different sources of the data, repeatedly stated that the course provided them with a limited teaching time opportunity. In the anonymous course evaluation form, for instance, a participant wrote:

It gives me a few opportunities to practice teaching and learn how to apply the teaching methods and approaches.

Moreover, during the interview, Yara said:

One of the challenges and actually it's the only challenge ... that we were given only 20 minutes for teaching. Since it's a practicum course, I would expect longer time than this, especially with the fact that it's a teaching program. So, even though I have teaching experience, I would love to put the things that newly added to my knowledge into practice.

Haifa, however, believes that the real challenge is the policy itself, as she expressed during the interview:

I know it's the policy that restricted it to only 20 minutes, but I think that policy should be revised because even in my BA course, which was three years ago in this university and my practice was in the institute, we had the chance to teach for one complete hour.

A participant in the evaluation form indicated that the reflective portfolio as a compulsory assignment required them to reflect on 30 hours of teaching without providing them a chance to teach for that length of time. When the form asked her about what she perceives as a drawback about the course, she wrote:

No opportunity to actually teach for 30 hours in the institute's classes.

\section{Changes Needed to Enhance the Effectiveness of the Course}

The participants suggested several changes to enhance the effectiveness of the course. They believe that increasing the teaching practice time is the most critically needed change $(42.9 \%)$. The following chart shows all the suggested changes.

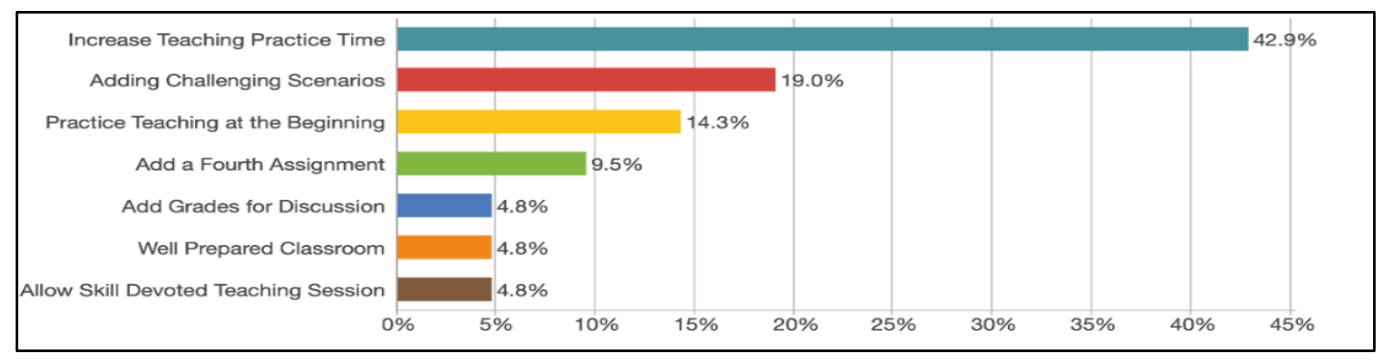

Figure 6. Changes Needed to Enhance the Effectiveness of the Course 
The participants strongly called for increasing the permissible teaching practice time. For instance, in one of the course evaluation forms, a participant reported:

I believe that a practicum course should solely rely on practice. So, what I would change about it would be the work the students need to do. It should involve more practice of teaching and less paperwork.

Yara, in the interview, brought up another suggestion, which is discussing challenging teaching scenarios in class:

maybe thinking of really difficult or challenging teaching scenarios that might actually happen in actual classrooms and finding solutions around being in this challenge by brainstorming or creating solutions for it.

\section{Discussion}

TP courses can be very beneficial to student-teachers. Being in line with many of the previous studies (Köksal \& Genç, 2019; Ulla, 2016; etc.), the results of this study highlighted the significance of $\mathrm{TP}$ in helping student-teachers to develop their teaching skills. Classroom discussions were the most prominent helpful aspects in the course for the participants of this study. Köksal and Genç (2019) study confirmed that TP raises student-teachers awareness about their strengths and weaknesses. The researcher believes that student-teachers could reach that awareness through both discussion and observation as the findings indicated. A possible explanation for this might be that student-teachers interact efficiently and freely with their peers in both situations.

Regarding the instructional benefits, three of them show alignment with findings from previous studies. For instance, (Alamri, 2018) reported selecting appropriate teaching methods as one of the skills related to classroom teaching experience. In this study, being introduced to practical teaching tips and techniques was the main gained instructional benefit. This finding might be factual because TP affords a good chance for student-teachers to have real teaching situations where they can experiment with different instructional approaches. Knowing classroom management techniques and designing proper activities were also found in both this and Alamri study. That can be expected as these are two of the main practical aspects of TP, where student-teachers are exposed to actual classroom teaching experience. Interestingly, participants in Alamri study reported improving four different school environment skills: dealing with teaching load and school administrative staff, compatibility with classroom's teacher, and commitment to the school system. In contrast, this study participants mentioned only one aspect related to school environment skills, which is dealing with technology. This difference in the reported results might be resulting from the difference in the teaching practice duration in both situations.

The findings showed that peer observation report is the most effective evaluation method as perceived by the participants. However, this finding contradicts results from previous studies. For example, Merç (2015) found that writing observation and reflection reports from the studentteachers perspective is among the less effective performance measures. The participants believe that observation reports can be a powerful tool for professional development purposes only. While reflective portfolio comes second in this study, it is the most effective measure in Merç's followed by the university's supervisor visit and evaluation by peer teachers. Participants of this study suggested classroom discussion to be one of the evaluation methods. This suggestion might 
sound valid because the reflective teaching portfolio has most of the weight of the grades (40) while the other two methods have less weight (30 for each). As stated in the analysis section, teaching practice time is limited to 20 minutes, whereas student-teachers must reflect upon 30 hours. Therefore, students believe that changing grades distribution might be a sound solution. According to the participants, the reflective portfolio should have less marks and classroom discussion must have some grades.

Concerning the challenges to the course, as we mentioned earlier, the participants emphasized the shortness of teaching timescale. This is in line with findings from Ulla (2016) study, which claimed that EFL student-teachers do not have enough time to practice teaching. Having enough time to practice teaching for student-teachers can be essential. As stated in Çapan (2014), student-teachers must have sufficient opportunities to practice teaching before becoming qualified teachers. However, Alamri (2018) reported different results. Alamri found the following challenges: preparing daily lesson planning, presenting the lessons, and preparing quizzes. These differences in findings might be resulting from the variance of both TP courses' length. Participants in Alamri study practiced teaching for four days weekly throughout the semester. In contrast, participants of this study had 20 minutes to practice teaching. Hence different findings occurred in terms of the course challenges.

It might be apparent that the participants suggested the changes above to overcome the challenges they reported. Increasing the teaching practice time was frequently mentioned in all data sources for this study. That might be rational given that student-teachers must reflect upon 30 hours of teaching in the primary assignment when they had only 20 minutes to practice teaching in the university classes. Considering that some students did not have previous teaching experience, allocating $40 \%$ percent of the marks to an assignment that required 30 hours of teaching was challenging to them. What made it more challenging is that they only had a chance to teach for a short amount of time. Similarly, participants in Ulla (2016) research also suggested decision-makers to consider giving more time to practice teaching. However, Alamri (2018) study revealed different suggestions for changes, given Alamri participants stated other challenges. Issues like preparing daily lesson planning, presenting the lessons, preparing quizzes, dealing with the teaching load, and dealing with the school administration staff. It is worth mentioning that in the TP course in Alamri (2018) study, students spend four days weekly in schools teaching from 7:00 AM to 1:00 PM, then, they continue their afternoon study classes from 4:00 PM to 9:45 PM. Despite the course layout differences in Alamri study and this study, participants reported adding challenging teaching situations as a needed change in both studies.

\section{Conclusion}

To conclude, this study explored the perspective of student-teachers in a Saudi university about the benefits and challenges of a TP course to help enrich the literature on TP in TESOL. Practical teaching was the most helpful part of the course, and the most appropriate evaluation method was peer-observation reports. Besides, the limitedness of the teaching timeframe was the major challenge and hence the main suggested change was increasing the teaching practice time. As presented in the previous sections, there are several instructional benefits for this TP course that teacher educators worldwide find relevant and useful. It is worth mentioning that the most frequently repeated challenge, which is limited teaching time, can be dealt with through adapting some of the following recommendations. Firstly, the program management team may think about 
increasing the teaching practice time to satisfy the required 30 hours of teaching to reflect upon by offering ten-hour direct contact with students. These ten hours require 20 hours of preparation, which is a total of 30 hours that are needed in the reflective portfolio assignment. Secondly, the introduction of a parallel practicum course in the following semester to have two practicum courses might be a good solution too. The program management team can structure these two courses in a way that one of them focuses on the theoretical aspects of language teaching and the other one on the teaching practices. Thirdly, imposing a pre-requisite of having at least a full semester teaching experience in the five years before enrolment as an acceptance criterion on the course.

In conclusion, TESOL researchers needs to conduct further research on the importance of peer observation reports due to the contradicting results of this research and previous studies. Investigating the rationale behind this contradiction and the significance of peer observation, seems to be needed. Finally, TP trainers and institutional management can participate in future research so that better and more effective plans are put in place to overcome challenges and improve practicum training quality.

\begin{abstract}
About the author
Dr. Khadija A. Alamoudi is a full-time assistant professor at the ELI, King Abdulaziz University, Jeddah, Saudi Arabia. She specializes in educational evaluation, EFL teacher evaluation, and EFL teacher professional development. Her research focuses on different aspects related to ELT teacher such as: performance evaluation, identity, and professional development. She also had some works on both theoretical and applied linguistics. https://orcid.org/0000-00028466-0967
\end{abstract}

\title{
References
}

Alamri, H. R. H. (2018). Challenges in Practicum: Views and Perceptions of EFL Pre-service Teachers towards Field Experience Skills in Real Classrooms. Arab World English Journal, 9(1), 146-162. DOI: https://dx.doi.org/10.24093/awej/vol9no1.11

Alnajami, M. L. (2018). Effectiveness of the Current EFL Practicum: Insights from University Mentors, School Mentors and English Language Majored Students at the University of Jeddah. International Journal of Psycho-Educational Sciences, 7(3), 47-55.

Çapan, S. A. (2014). Pre-service English as a foreign language teachers' belief development about grammar instruction. Australian Journal of Teacher Education, 39(12). DOI10.14221/ajte.2014v39n12.9

Creswell, J. W., \& Poth, C. N. (2017). Qualitative inquiry and research design: Choosing among five approaches. London, UK: SAGE Publications, Inc.

Crotty, M. (1998). The foundations of social research: Meaning and perspective in the research process. London, UK: Sage Publications Ltd.

Furlong, V., Hirst, P., \& Pocklington, K. (1988). Initial Teacher Training and the Role of the School. Philadelphia: Open University Press.

Gujjar, A. A., Ramzan, M., \& Bajwa, M. J. (2011). An evaluation of teaching practice: practicum. Pakistan Journal of Commerce and Social Sciences (PJCSS), 5(2), 302-318.

Haigh, M., Ell, F., \& Mackisack, V. (2013). Judging teacher candidates' readiness to teach. Teaching and Teacher Education, 34, 1-11. 
Köksal, D., \& Genç, G. (2019). Learning while teaching: Student teachers' reflections on their teaching practicum. Dil ve Dilbilimi Çalışmaları Dergisi, 15(3), 895-913. DOI: $10.17263 /$ jlls.631531

Mackenzie, N., \& Knipe, S. (2006). Research dilemmas: Paradigms, methods and methodology. Issues in educational research, 16(2), 193-205.

Merç, A. (2015). Assessing the Performance in EFL Teaching Practicum: Student Teachers' Views. International Journal of Higher Education, 4(2), 44-56.

Neuman, L. W. (2007). Social research methods: Qualitative and quantitative approaches. India: Pearson Education.

Ulla, M. B. (2016). Pre-service teacher training programs in the Philippines: The studentteachers practicum teaching experience. EFL journal, 1(3), 235-250.

Yuan, R., \& Lee, I. (2014). Pre-service teachers' changing beliefs in the teaching practicum: Three cases in an EFL context. System, 44, 1-12. DOI: 10.1016/j.system.2014.02.002. 